\title{
二氧化碳参与的环化反应最新研究进展
}

\author{
张文珍* 张宁郭春晓吕小兵
}

(大连理工大学精细化工国家重点实验室 大连 116024)

\begin{abstract}
摘要 二氧化碳是一种储量丰富且廉价易得的可再生碳一资源. 将二氧化碳高效转化成高附加值化学品的有机合成方 法学研究目前已经成为最为活跃的研究方向之一. 由于环化反应种类的多样性以及环化产物在众多生物活性分子结构 中的广谱性, 二氧化碳参与的环化反应也深受广大研究者重视. 综述了最近二氧化碳参与的环化新反应合成内酰胺、 内酯、邻苯二甲酰亚胺、环状酸䣶、苯并噻唑及苯并咪唑等杂环化合物，同时也介绍了一些二氧化碳作为反应底物但 不参与成环过程合成环状羧酸的新反应.
\end{abstract}

关键词 二氧化碳; 环化反应; 绿色化学; 有机合成; 杂环化合物

\section{Recent Progress in the Cyclization Reactions Using Carbon Dioxide}

\author{
Zhang, Wenzhen* Zhang, Ning Guo, Chunxiao Lü, Xiaobing \\ (State Key Laboratory of Fine Chemicals, Dalian University of Technology, Dalian 116024)
}

\begin{abstract}
Carbon dioxide is a cheap, abundant and renewable $\mathrm{C}_{1}$ feedstock. Methodology study on the transformation of carbon dioxide into highly value-added chemicals has become one of the most active topics in organic chemistry. Owing to the diversity of cyclization reaction and vast occurrence of various heterocyclic motifs in biologically important molecules, the cyclization reactions using carbon dioxide have gained much attention. This review therefore aims to principally describe the recent progress in the new cyclization reactions using carbon dioxide as feedstock to synthesize lactams, lactones, cyclic anhydrides, benzothiazoles, benzimidazoles and other heterocyclic compounds.
\end{abstract}

Keywords carbon dioxide; cyclization reaction; green chemistry; organic synthesis; heterocycles

二氧化碳作为储量丰富、廉价易得的可再生碳一资 源其催化转化得到了化学工作者的广泛关注 ${ }^{[1 \sim 5]}$. 将二 氧化碳高效转化成高附加值化学品的有机合成新方法 学研究已经成为目前最为活跃的研究方向之一. 虽然二 氧化碳固有的热力学及动力学稳定性限制了它作为碳 一合成子的广泛应用, 但已初步建立起来的多种二氧化 碳新有机反应体系可将二氧化碳成功转化成在制药等 精细化工中有着重要用途的合成中间体 ${ }^{[6 ~ 11]}$. 由于环化 反应种类的多样性以及环化产物在众多生物活性分子 结构中的广谱性，二氧化碳参与的环化反应也深受广大 研究者重视 ${ }^{[12,13]}$. 目前二氧化碳与环氧烷烃或炔丙醇反 应合成环状碳酸酯、与氮杂环丙烷或炔丙胺反应合成噁 唑啉酮、与邻氨基苯腈反应合成喹唑啉二酮这三大类反 应的新催化体系研究较多, 已有很多综述从不同角度做
了概括总结 ${ }^{[12 ~ 18]}$, 本文将不再主要介绍. 最近发展起来 的二氧化碳参与的其他多种环化新反应可高效合成多 种杂环化合物. 如在非还原性条件下，二氧化碳可通过 内酰胺化、内酯化、环加成等反应合成内酰胺、内酯、 邻苯二甲酰亚胺、环状酸䣶等(图 1); 在硅烷等还原剂的 存在下，邻苯二胺或邻氨基苯硫醇可与二氧化碳进行还 原性羧化环化反应得到苯并咪唑或苯并噻唑类化合物. 以上环化反应在建立起新的二氧化碳活化转化模式的 同时，也为制备杂环化合物提供了更为绿色的合成路 线. 本文按照产物的种类、反应底物类型分层次对最近 二氧化碳参与的环化新反应及其机理进行综述，同时也 介绍了一些二氧化碳作为反应底物但不参与成环过程 合成环状羧酸的新反应.

\footnotetext{
* Corresponding author. E-mail: zhangwz@dlut.edu.cn Received January 14, 2017; revised March 19, 2017; published online April 1, 2017.
}

Project supported by the Fundamental Research Funds for the Central Universities (No. DUT15LAB21) and the Program for Changjiang Scholars and Innovative Research Team in University (Nos. T2011056, IRT13008).

中央高校基本科研业务费专项资金(No. DUT15LAB21)和教育部长江学者与创新团队发展计划(Nos. T2011056, IRT13008)资助项目。 


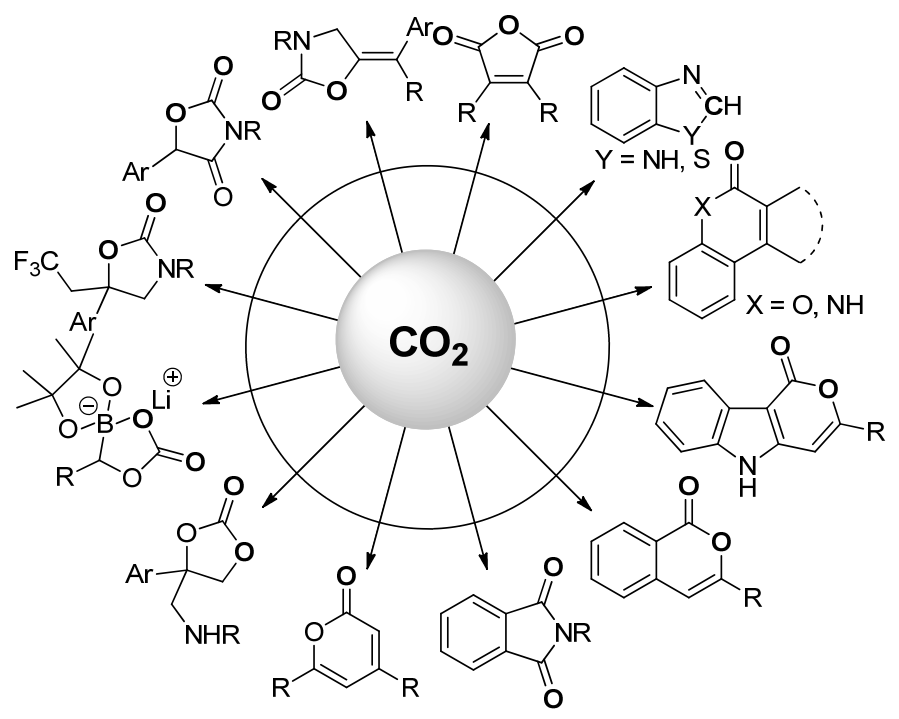

图 1 二氧化碳参与的环化新反应合成的杂环化合物

Figure 1 Heterocyclic compounds from new cyclization reactions using carbon dioxide

\section{1 合成内酰胺类化合物}

通过 $\mathrm{sp}^{2}$ 碳氢键的二氧化碳羧化反应合成内酰胺最 近取得了重要的研究进展. 相比于端炔烃中 $\mathrm{sp}$ 碳氢键 的二氧化碳羧化反应, 芳烃或烯烃中 $\mathrm{sp}^{2}$ 碳氢键和烷烃 中 $\mathrm{sp}^{3}$ 碳氢键的二氧化碳羧化反应条件较为苛刻 $[19,20]$. 在芳烃或烯烃底物中引入氨基等官能团, 通过形成内酰 胺等环状化合物的 $\mathrm{sp}^{2}$ 碳氢键二氧化碳羧化反应在热力 学上更有利.

2016 年初, 余达刚课题组 ${ }^{[21]}$ 报道了二氧化碳参与 的邻烯基/杂环芳基苯胺中 $\mathrm{sp}^{2}$ 碳氢键的内酰胺化反应 (Scheme 1). 仅在叔丁醇钠作为碱, 二乙二醇二甲醚为 溶剂, $140{ }^{\circ} \mathrm{C}$ 的反应条件下，一系列邻烯基/杂环芳基苯 胺化合物 1 与 $101 \mathrm{kPa}$ 的二氧化碳进行 $\mathrm{sp}^{2}$ 碳氢键的内 酰胺化反应, 以较高收率得到 2-喹啉酮类化合物 2. 此 反应底物适用性广, 产物易于衍生化, 操作简便, 易于 放大, 可用于构建多种重要药物分子(如 2c)及重要前体 (如 2a 和 2d) (Scheme 1). 作者首次明确提出了 “ $\mathrm{CO}_{2}=$ $\mathrm{CO}+\mathrm{O}$ (氧化剂)” 的概念 ${ }^{[22]}$. 相比于传统的一氧化碳作 为羰基源的钯催化邻烯基/杂环芳基苯胺 $\mathrm{sp}^{2}$ 碳氢键的氧 化羰基化反应，二氧化碳为羰基源的内酰胺化反应在无 过渡金属参与且氧化还原中性的条件下进行, 对环境友 好, 也更容易在精细化学品工业中应用. 机理研究表明 在此反应体系中可能生成高活性的邻烯基/杂环芳基苯 基异腈酸酯中间体 $\mathbf{3}$, 然后异构化为内酰胺产物 (Scheme 1).

随后, 席婵娟课题组 ${ }^{[23]}$ 报道了无金属参与的邻芳 基苯胺中 $\mathrm{sp}^{2}$ 碳氢键与二氧化碳的内酰胺化反应 (Scheme 2). 在 1,5,7-三氮杂二环 [4.4.0]癸-5-烯(TBD)和

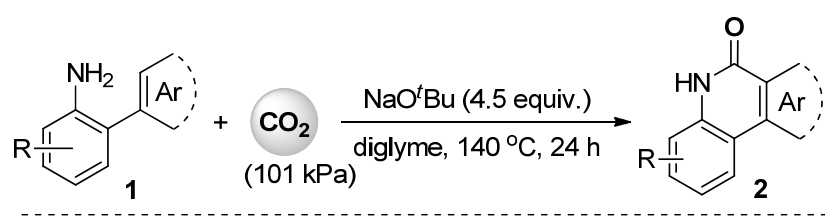<smiles>O=c1cc(-c2ccccc2)c2ccccc2[nH]1</smiles>

2a, $84 \%$<smiles></smiles>

2b, $98 \%$<smiles>O=c1cc(-c2ccccc2)c2cc(Cl)ccc2[nH]1</smiles>

2c, $78 \%$<smiles>O=c1cc(-c2cccc(Cl)c2)c2cc(Br)ccc2[nH]1</smiles>

2d, $81 \%$

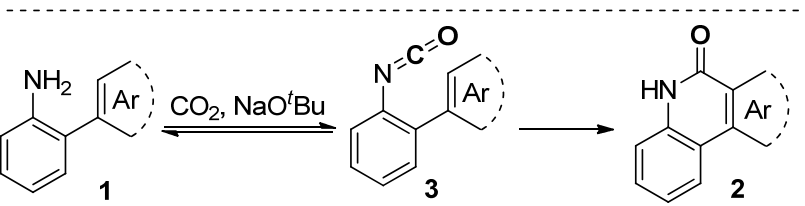

图式 1 二氧化碳参与的邻烯基/芳基苯胺中 $\mathrm{sp}^{2}$ 碳氢键的内酰 胺化反应

Scheme 1 Lactamization of $\mathrm{sp}^{2}-\mathrm{C}-\mathrm{H}$ bonds in 2-alkenyl and 2-aryl anilines with carbon dioxide

三氟甲磺酸甲酯(MeOTf)的共同作用下，一系列邻苯基/ 杂环芳基苯胺化合物 4 与 $101 \mathrm{kPa}$ 的二氧化碳在邻二氯 苯中于 $140{ }^{\circ} \mathrm{C}$ 反应 $12 \mathrm{~h}$, 以较高收率得到相应的内酰胺 产品 5. 上述叔丁醇钠反应系统中不适用的邻苯基苯胺 底物在此 TBD/MeOTf 体系中能顺利进行 $\mathrm{sp}^{2}$ 碳氢键的 内酰胺化反应. 反应收率主要受底物电子效应的影响, 富电子的邻芳基苯胺化合物反应活性更高. 经过系统的 对照实验, 作者给出了可能的反应机理(Scheme 2), 邻 芳基苯胺首先与 TBD 二氧化碳加合物 ${ }^{[24]} 1$ equiv.的 $\mathrm{MeOTf}$ 反应生成氨基甲酸酯 $\mathbf{6}$, 随后 $\mathbf{6}$ 在高温下脱去甲 
醇生成的邻芳基苯基异氧酸醌(7)未直接进行环化反应, 而是先和过量的 MeOTf 反应得到高活性的反应中间体 8 后再发生环化反应得到 6-甲氧基菲啶中间体 9 , 随后 9 与上一步产生的三氟甲磺酸反应得到 2-喹啉酮产物.
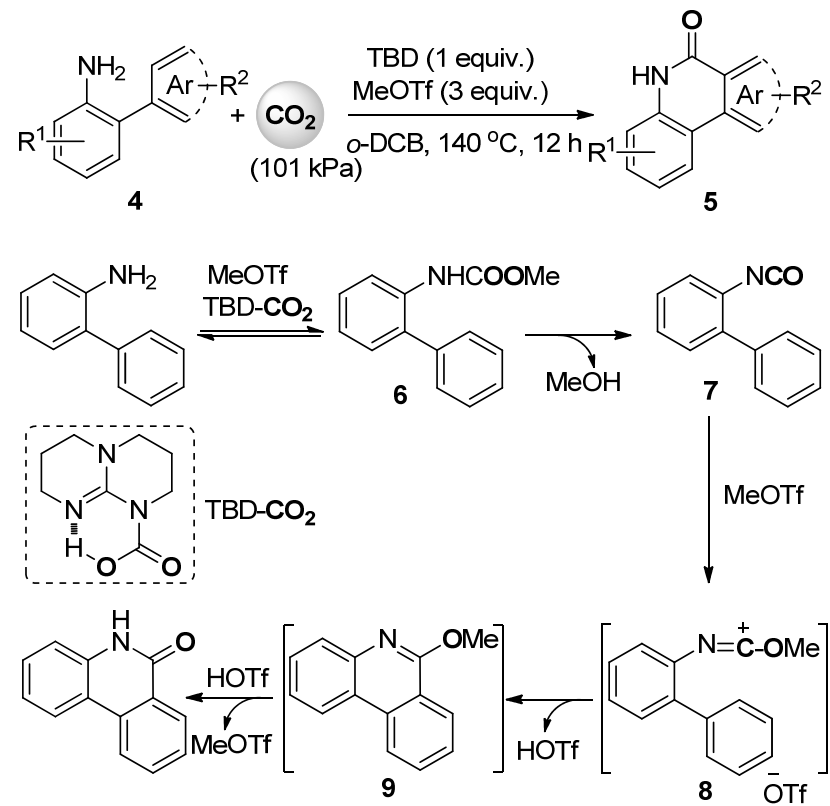

图式 2 无金属参与的邻芳基苯胺中 $\mathrm{sp}^{2}$-碳氢键与二氧化碳的 内酰胺化反应

Scheme 2 Metal-free lactamization of $\mathrm{sp}^{2}-\mathrm{C}-\mathrm{H}$ bonds in 2-arylanilines with carbon dioxide

最近, 成江课题组 ${ }^{[25]}$ 报道了钯催化邻碘苯胺 $(\mathbf{1 0})$ 、 $N$-对甲基苯磺酰腙 11 和 $101 \mathrm{kPa}$ 的二氧化碳的多组分反 应(Scheme 3), 高效合成了一系列 4-芳基-2-喹啉酮化合 物 12. 此多组分反应形成了包含两组碳碳单键, 一组碳 碳双键和一组碳氮单键共四组新的化学键. 作者推测的 反应机理主要为邻碘苯胺与 $N$-对甲基苯磺酰腙在叔丁 醇钠作为碱及钯催化下通过钯卡宾的迁移插入形成邻 烯基苯胺化合物 13 (Scheme 3), 然后再与二氧化碳反应 经异氰酸酯中间体得到内酰胺产物. 由于在最优反应条 件下邻碘苯基异氧酸酯可与 $N$-对甲基苯磺酰腙反应得 到 4-芳基-2-喹啉酮产物, 作者也未排除邻碘苯胺先于 二氧化碳反应生成邻碘苯基异氧酸酯, 然后再与 $N$-对 甲基苯磺酰腙进行迁移插入/内酰胺化这一反应途径 (Scheme 3).

\section{2 合成内酯类化合物}

\section{$2.1 \mathrm{sp}^{2}$ 碳氢键内酯化反应}

2013 年, Iwasawa 课题组 ${ }^{[26]}$ 报道了二价钯催化 2-差琴 基苯乙烯类化合物中烯基 $\mathrm{sp}^{2}$ 碳氢键与二氧化碳的直接 羧化反应(Scheme 4). 在 $5 \mathrm{~mol} \%$ 醋酸钯为催化剂, 3

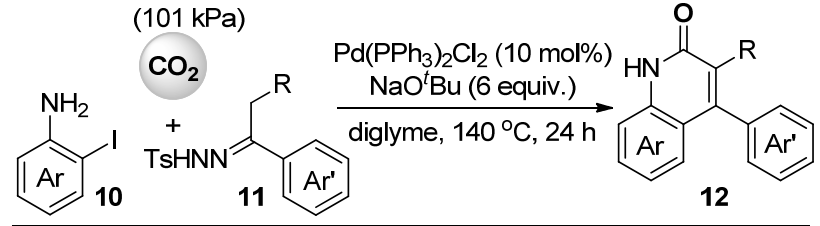

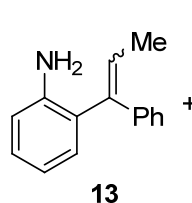

13

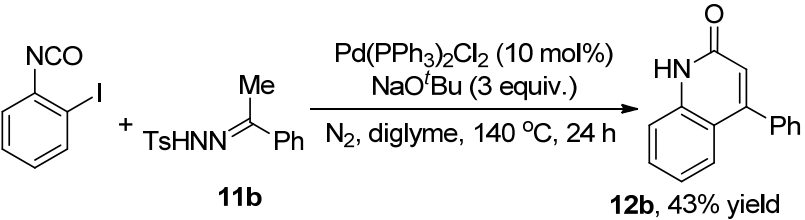

图式 3 钯催化邻碘苯胺、 $N$-对甲基苯磺酰腙和二氧化碳的多 组分反应

Scheme 3 Palladium-catalyzed multi-component reactions of 2 -iodoanilines, $N$-tosylhydrazones and carbon dioxide

equiv.的碳酸铯作为碱，二乙二醇二甲梄为溶剂， $100{ }^{\circ} \mathrm{C}$ 的最优反应条件下，包含给电子、吸电子或杂环取代基 的一系列 2-羟基苯乙烯化合物 $\mathbf{1 4}$ 与 $101 \mathrm{kPa}$ 的二氧化 碳进行 $\mathrm{sp}^{2}$ 碳氢键内酯化反应，以中等到较高收率得到 相应的香豆素类化合物 15. 反应机理研究表明底物 14a 首先与醋酸钯和碳酸铯反应生成烯基环钯配合物 16 , 当量反应分离得到了此配合物, $X$ 射线单晶衍射也确认 了其分子结构. 随后进行的二氧化碳羧化配合物 16 中 碳钯键形成羧基钯中间体 17 的过程虽然是可逆的，对 照实验也证明 17 很容易脱羧直接回到热力学上更稳定 的配合物 16, 但反应过程中 17 可与另外一分子的反应 底物和碳酸铯作用，释放出产物内酯的同时再生反应活 性中间体 16, 使反应朝着羧化方向进行, 完成催化循环 (Scheme 4).

最近, 余达刚课题组 ${ }^{[27]}$ 在之前 $\mathrm{sp}^{2}$ 碳氢键的内酰胺 化反应的基础上，发展了无过渡金属参与的邻杂环芳基 苯酚及邻羟基苯乙烯中 $\mathrm{sp}^{2}$ 碳氢键与二氧化碳的内酯化 反应(Scheme 5). 一系列邻咪唑并[1,2- $a$ 吡啶基苯酚 18 在叔丁醇钾作为碱时与 $101 \mathrm{kPa}$ 的二氧化碳进行 $\mathrm{sp}^{2}$ 碳 氢键内酯化反应, 高收率地得到并四环结构的内酯化合 物 19. 作者推测的反应机理为底物 18 首先与叔丁醇钾 反应得到酚钾 20 后，连续与两分子二氧化碳反应得到 中间体 22, 随后分子内亲核进攻得到内酯产物 19 (Scheme 5). 此无过渡金属参与的反应体系在 $N, N$-二甲 基甲酰胺(DMF)作为溶剂时也适用于富电子的邻羟基 苯乙烯底物中 $\mathrm{sp}^{2}$ 碳氢键与二氧化碳的内酯化反应合成 香豆素类化合物 15 (Scheme 5). 


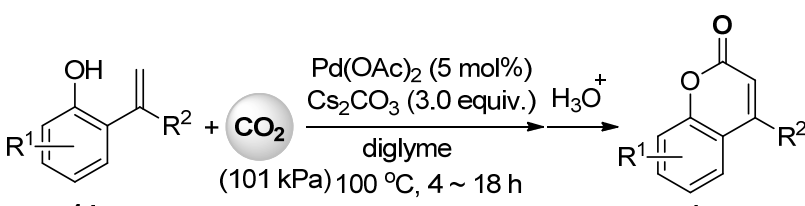

14 $(101 \mathrm{kPa}) 100^{\circ} \mathrm{C}, 4 \sim 18 \mathrm{~h}$

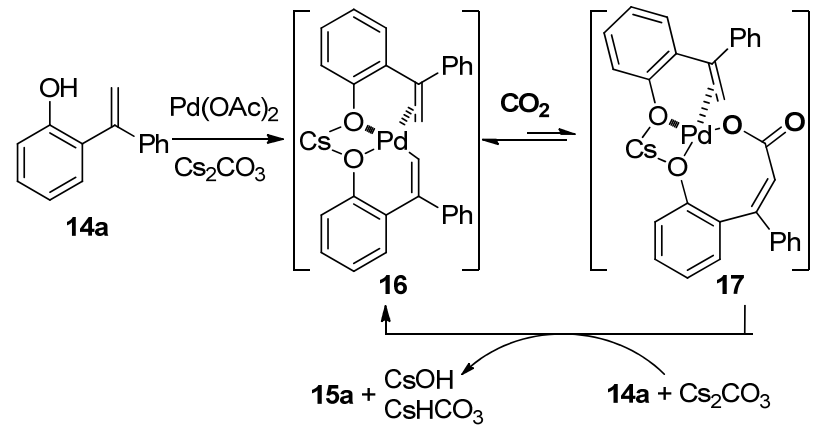

图式 4 钯催化邻羟基苯乙烯 $\mathrm{sp}^{2}$-碳氢键与二氧化碳的内酯化 反应

Scheme 4 Palladium-catalyzed lactonization of $\mathrm{sp}^{2}-\mathrm{C}-\mathrm{H}$ bonds in 2-hydroxystyrenes with carbon dioxide
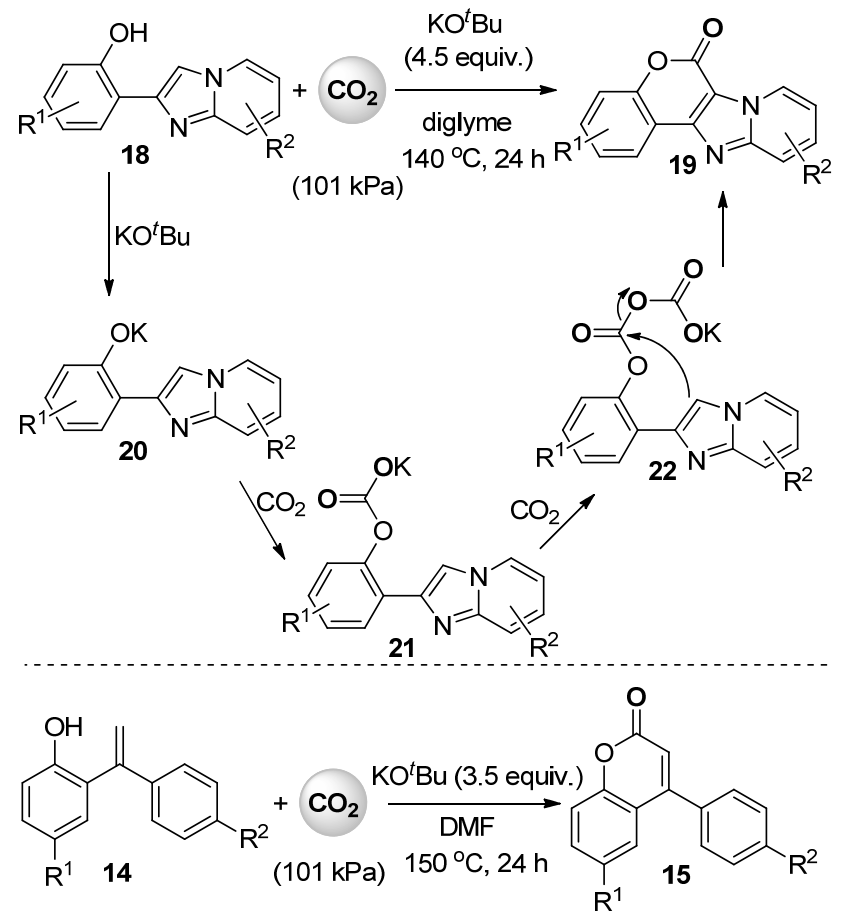

图式 5 无过渡金属参与邻杂环芳基苯酚及邻羟基苯乙烯中 $\mathrm{sp}^{2}$-碳氢键与二氧化碳的内酯化反应

Scheme 5 Transition-metal-free lactonization of $\mathrm{sp}^{2}-\mathrm{C}-\mathrm{H}$ bonds in 2-arylphenols/2-hydroxystyrenes with carbon dioxide

2015 年, Skrydstrup 课题组 ${ }^{[28]}$ 报道了无金属参与的, $\mathrm{TBD}$ 催化 2-炔基吲哚类化合物 $\mathbf{2 3}$ 与二氧化碳的羧化环 化反应高收率合成并三环的内酯化合物 24 (Scheme 6). 当 $\mathrm{R}^{2}$ 为芳基时, 反应只需使用 0.3 equiv. 的 TBD 就可高 效进行. 当 $\mathrm{R}^{1}$ 为烷基取代时底物的反应活性较差, 需要 将 TBD 的用量提高到 1 equiv. 通过一系列对照实验作者
提出了可能的反应机理(Scheme 6). 首先底物 $\mathbf{2 3}$ 中吲哚 环上 $\mathrm{sp}^{2}$ 碳氢键被 TBD二氧化碳加合物羧化形成中间体 25, 然后 25 重新芳构化后得到的 2-炔基-3-羧基吲哚中 间体 26 进行 6-endo-dig 型分子内环化反应得到内酯产 物 24 .

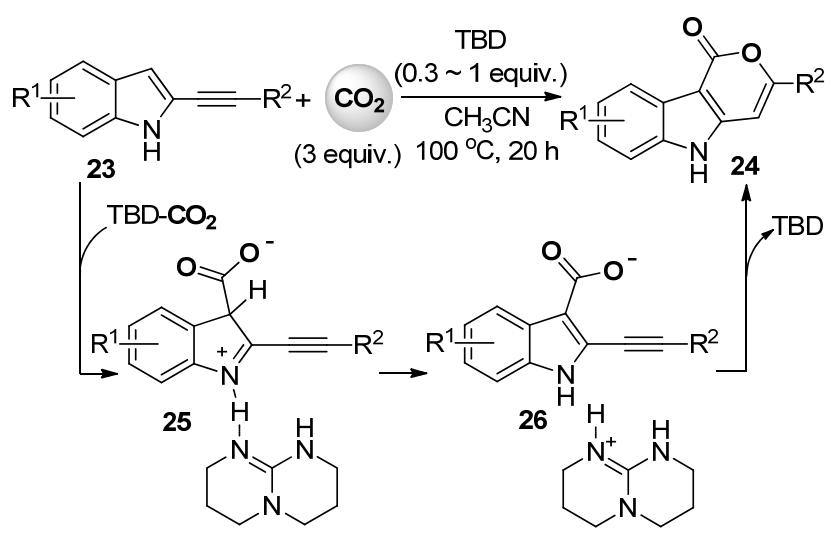

图式 $6 \mathrm{TBD}$ 催化 2-炔基吲哚与二氧化碳的羧化环化反应 Scheme 6 TBD-catalyzed carboxylative cyclization reactions of 2-alkynyl indoles with carbon dioxide

\section{2 芳炔参与的多组分环化反应}

芳炔作为高活性的反应中间体已广泛应用于多组 分有机合成反应中 ${ }^{[29]}$. 芳炔通常表现出很高的亲电性, 容易与亲核试剂先反应得到芳基负离子中间体，然后再 与各种亲电试剂反应得到 1,2-二取代的芳烃. 早在 2006 年已有芳炔与亚胺及二氧化碳的三组分环化反应报 道 ${ }^{[30]} .2014$ 年, Kobayashi 课题组 ${ }^{[31]}$ 报道了氮杂环卡宾铜 配合物催化的芳炔、端炔和二氧化碳的多组分环化反应 以中等到较高收率合成异香豆素类化合物 28 (Scheme 7). 此反应体系采用碘化亚铜与膦配体作为催化剂时, 不但羧化产物收率低, 5-exo-dig 和 6-endo-dig 型环化产 物的选择性也很差. 当使用氮杂环卡宾铜配合物作为催 化剂, 在乙腈和四氢呋喃的混合溶剂中反应可高收率高 选择性地得到 6-endo-dig 型环化产物. 结合已有的报道 及对照实验，作者提出的催化反应机理见 Scheme 7. 端 炔与铜配合物首先在碳酸铯作用下形成炔铜配合物. 虽 然我们课题组报道了二氧化碳可以插入此炔铜配合物 的 $\mathrm{C}_{\mathrm{sp}}-\mathrm{Cu}$ 键形成炔酸铜化合物 ${ }^{[32]}$, 但在此反应中作者 未观察到相关产物. 芳炔前体 27 在 $\mathrm{CsF}$ 作用下形成芳 炔后插入炔铜配合物形成邻炔基芳基铜中间体 29, 二 氧化碳插入 29 中的碳铜键得到邻炔基芳甲酸铜中间体 30 后进行 6-endo-dig 型分子内环化反应形成内酯配合物 31. 由于使用氝代的端炔反应时异香豆素产物中没有检 测到気原子的引入, 所以作者认为铜配合物催化剂的再 生和释放出产品的过程不是通过 31 的质子化, 而是通 过 31 与铯盐的转金属化反应实现的(Scheme 7). 

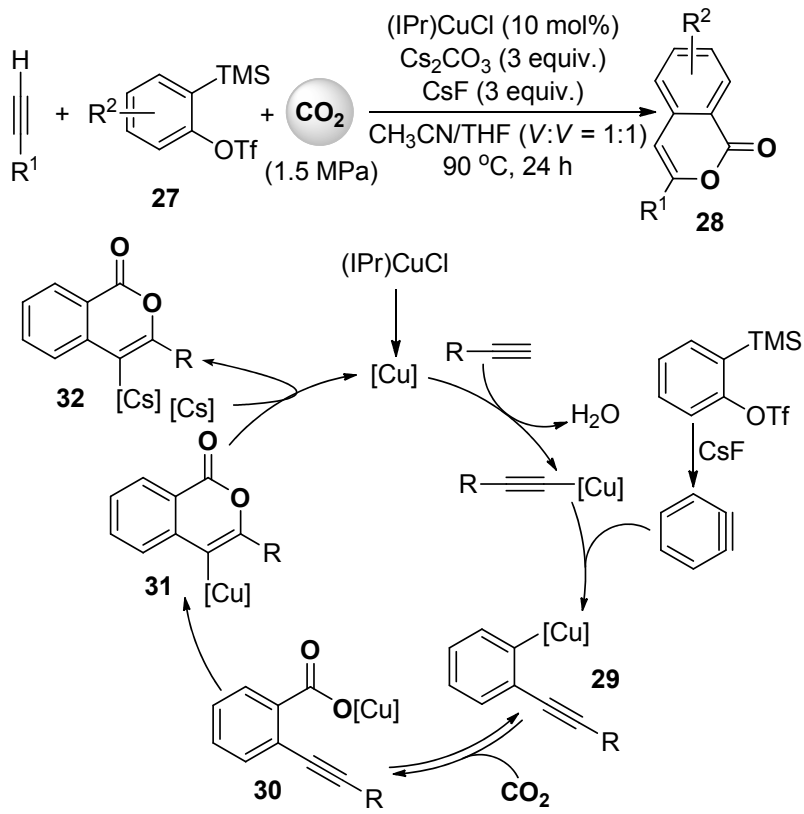

图式 7 铜催化芳炔、端炔和二氧化碳的多组分羧化环化反应

Scheme 7 Copper-catalyzed multi-component carboxylative cyclization reactions of arynes, terminal alkynes and carbon dioxide

\section{3 芳香酮参与的二氧化碳羧化/环化反应}

众所周知，在适当碱存在下，酮羰基 $\alpha$ 位碳氢键可 经烯醇式中间体与二氧化碳进行羧化反应得到 $\beta$ 酮 酸 ${ }^{[33]}$. 基于此反应, 许多炔基酮与二氧化碳的羧化环化 反应已被报道 ${ }^{[34 ~ 36]} .2015$ 年, 我们课题组 ${ }^{[37]}$ 发展了 1,8二氮杂二环十一碳-7-烯(DBU)促进的邻羟基苯乙酮 33 及邻乙酰胺基苯乙酮 34 与 $3 \mathrm{MPa}$ 的二氧化碳的羧化环 化反应(Scheme 8), 高选择性地合成了一系列含有不同 取代基的 4-羟基香豆素类化合物 35 和 4-差基-2-喹啉酮 类化合物 36. 其中在邻乙酰胺基苯乙酮与二氧化碳反 应中酰基发生了迁移。

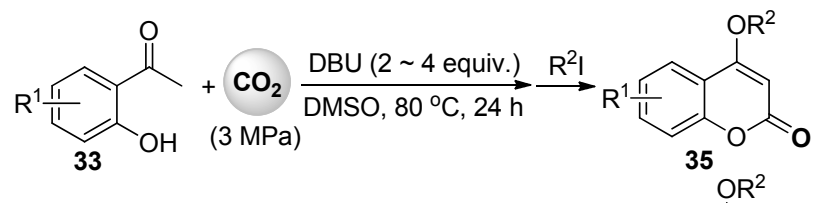

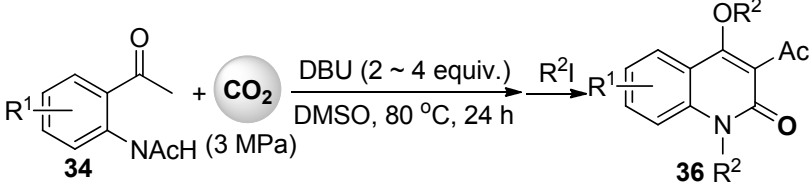

图式 $8 \mathrm{DBU}$ 促进的邻羟基/乙酰胺基苯乙酮与二氧化碳的羧 化环化反应

Scheme 8 DBU-promoted carboxylative cyclization reactions of 2-hydroxy and 2-acetamidoacetophenone with carbon dioxide

基于上述反应, 2016 年我们课题组 ${ }^{[38]}$ 发展了氟化铯 促进的丙烯基酮 37 经 $\gamma$ 位碳氢键与 $3 \mathrm{MPa}$ 的二氧化碳
的羧化环化反应(Scheme 9), 以中等至较高收率合成了 包含芳基、烷基及杂环等取代基的 2-吡喃酮化合物 38 . 通过 ${ }^{18} \mathrm{O}$ 标记的二氧化碳实验发现, 2-吡喃酮产物中只 有一个氧原子来自于二氧化碳. 依次推测可能的反应机 理是丙烯基酮 37 在碱作用下首先形成共轭结构的烯醇 式中间体 39, 然后经 $\gamma$ 位与二氧化碳䍨化反应后形成羧 基中间体 40, 在过量碱的作用下, 40 进一步脱质子后再 通过烯醇式氧原子对羧基亲核进攻完成分子内酯化反 应得到 2-吡喃酮产物(Scheme 9). 此反应也可能通过中 间体 39 与两分子的二氧化碳反应形成类似于 Scheme 5 中中间体 22 的中间体 $\mathbf{4 1}$, 经分子内亲核进攻得到内酯 产物. 丙烯基酮 37 自身二聚的副反应通过提高二氧化 碳压力和降低底物浓度得到了有效抑制.

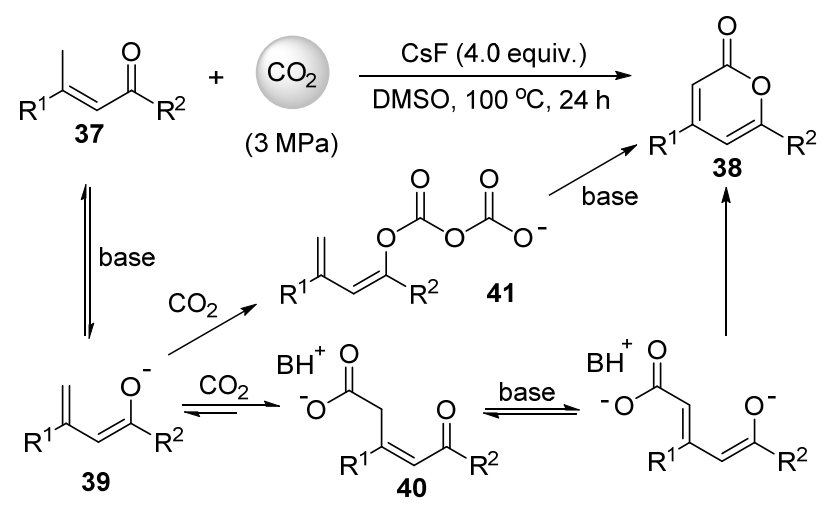

图式 9 丙烯基酮与二氧化碳的羧化环化反应 Scheme 9 Carboxylative cyclization reactions of substituted propenyl ketones with carbon dioxide

2015 年, Murakami 课题组 ${ }^{[39]}$ 报道了在紫外甚至可 见光驱动下，邻烷基苯基酮化合物 $\mathbf{4 2}$ 在室温下与 101 $\mathrm{kPa}$ 的二氧化碳进行羧化反应高收率合成了邻酰基苯乙 酸化合物 43 (Scheme 10). 作者推测的反应机理中受光 激发后的邻烷基苯基酮 $\mathbf{4 2}$ 中酮羰基篗取苯环邻位甲基 上的氢后先形成 $1,4-$ 双自由基中间体 $\mathbf{4 4}$ 后，立刻产生邻 苯碳醌中间体 $\mathbf{4 5}$, 其中顺式构型的 45 通过 1,5-氢迁移 回到原料 43 , 而反式构型的 45 与二氧化碳进行 [4+2] 环加成反应得到不稳定的羟基内酯产物 46 后, 经开环 异构化得到邻酰基苯乙酸产物 $\mathbf{4 3}$ (Scheme 10). 虽然此 反应从表观上看不属于环化反应，但作者认为反应过程 中包含二氧化碳参与的 $[4+2]$ 环加成形成内酯的过程.

\section{3 合成邻苯二甲酰亚胺}

2014 年, Biju 课题组 ${ }^{[40]}$ 报道了芳炔、异腈和 $101 \mathrm{kPa}$ 的二氧化碳的多组分环化反应合成邻苯二甲酰亚胺类 化合物 47 (Scheme 11). 作者推测的反应机理见 Scheme 11. 由于异腈具有较高的亲核反应活性，其亲核进攻原 


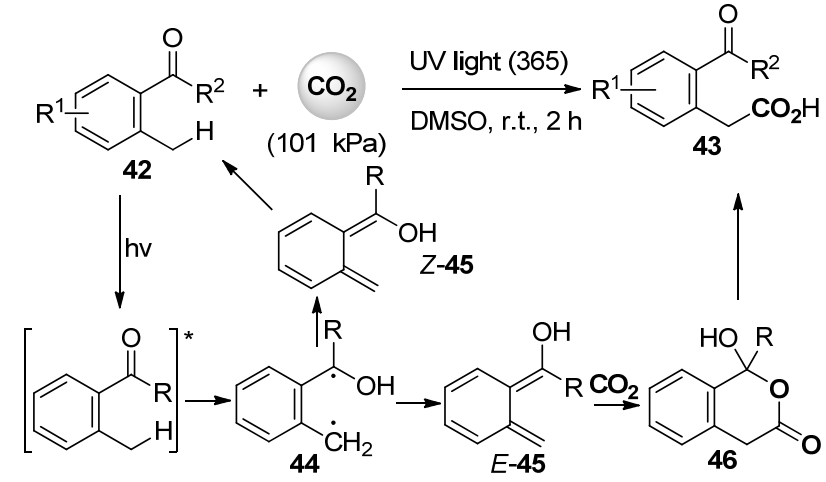

图式 10 光驱动邻烷基苯基酮与二氧化碳的羧化反应 Scheme 10 Light-driven carboxylation of 2-alkylphenyl ketones with carbon dioxide

位形成的芳炔中间体形成 1,3-两性离子中间体后再亲核 进攻二氧化碳得到中间体 48, 羧基氧分子内亲核进攻 闭环得到亚胺基异苯并呋喃酮 49. 随后在氟离子的作 用下, 49 开环后再次闭环形成热力学上更稳定的邻苯二 甲酰亚胺产物(Scheme 11).

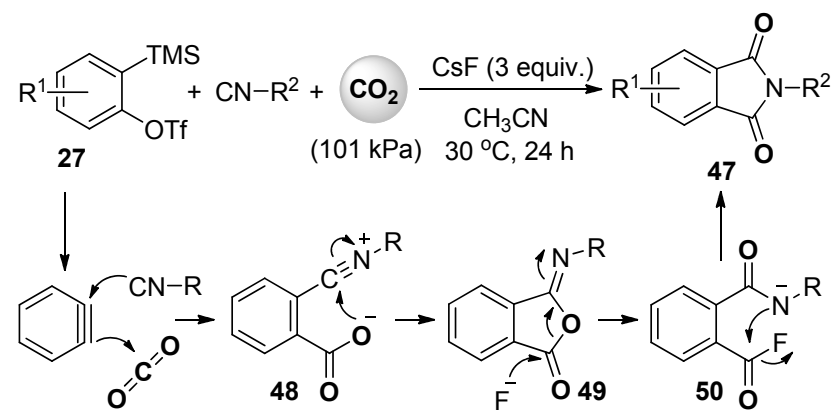

图式 11 芳炔、异腈和二氧化碳的多组分羧化环化反应

Scheme 11 Multi-component carboxylative cyclization reactions of arynes, isocyanides and carbon dioxide

\section{4 合成环状酸酐}

2014 年, Sakaki 和 Tsuji 课题组 ${ }^{[41]}$ 报道了镍催化内炔 与 $101 \mathrm{kPa}$ 二氧化碳的双羧化反应, 高收率合成了取代 的马来酸䣶化合物 51 (Scheme 12). 反应体系中联吡啶 作为配体, 锌粉作为还原剂, 溴化镁作为添加剂对酸䣶 产物的形成缺一不可.

通过密度泛函理论计算及对照实验, 作者推测此反 应的机理包括乙酰丙酮镍配合物首先被锌粉还原为高 活性的零价镍配合物后, 与内炔底物和一分子的二氧化 碳进行氧化加成得到经典的镍杂五元环内酯配合物 $\mathbf{5 2}$, 接着在锌粉和溴化镁的共同作用下，二价镍配合物 $\mathbf{5 2}$ 被还原成一价镍配合物 $\mathbf{5 3}$, 其中与镁原子成离子键的 羧基也配位在镍原子上. 随后第二分子的二氧化碳插入 碳镍键后形成中间体 54, 在锌粉的作用下, 54 中的一价 镍被还原成零价镍后继续进入下一轮催化循环, 释放出
的马来酸盐 55 经酸后处理形成马来酸酐产物(Scheme 12). 密度泛函理论计算表明，溴化镁在将二价镍配合 物 52 被还原成一价镍配合物 53 和第二分子二氧化碳插 入过程中起关键的促进作用.

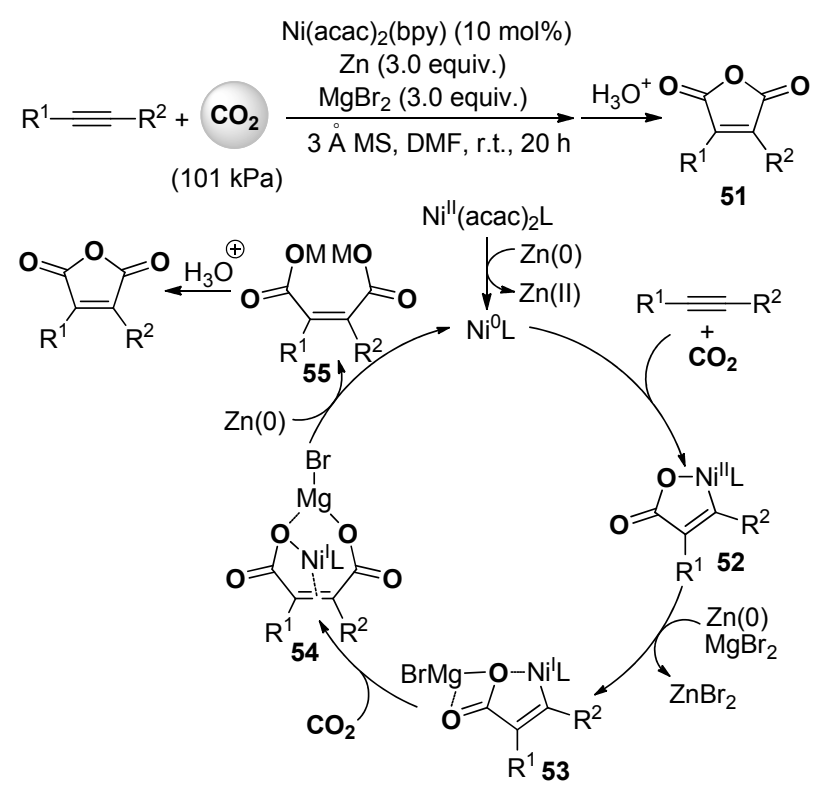

图式 12 镍催化内炔与二氧化碳的双羧化反应合成马来酸酐 Scheme 12 Nickel-catalyzed double carboxylations of internal alkynes with carbon dioxide to synthesize maleic anhydrides

\section{5 合成噁唑啉酮}

二氧化碳与与氮杂环丙烷或炔丙胺反应合成啞唑 啉酮是目前二氧化碳转化研究中最常见的一类重要反 应 $^{[14 \sim 18]}$. 最近研究者也发展了一些新的二氧化碳参与 的环化反应合成啞唑啉酮.

2016 年, Nevado 课题组 ${ }^{[42]}$ 报道了钯催化炔丙胺, 芳 基碘和 $101 \mathrm{kPa}$ 二氧化碳的多组分羧化环化反应 (Scheme 13), 以较高产率合成啞唑啉酮类化合物. 与传 统的路易斯酸催化的炔丙胺与二氧化碳羧化环化反应 不同的是, 此反应中利用零价钯与芳基碘氧化加成后得 到的二价钯配合物作为路易斯酸活化炔丙胺 56 中的碳 碳参键, 在促进羧化环化反应形成噁唑啉酮环后, 再经 还原消除过程在双键上引入芳基，得到最终的产物 57. 当使用端炔丙胺底物 58 时, 只需使用过量的芳基碘代 物和添加 $5 \mathrm{~mol} \%$ 的碘化亚铜, 将炔丙胺 56 反应体系中 的碱叔丁醇钠换成三乙烯二胺(DABCO), 便可在钯催 化下先进行 Sonogashira 偶联, 然后再进行多组分羧化 环化反应得到双键端位上引入两个相同芳基的噁唑啉 酮产物 59 (Scheme 13).

2016 年, 余达刚课题组 ${ }^{[43]}$ 首次实现了铜催化的二 氧化碳参与的烯丙胺选择性氧三氟甲基化反应 (Scheme 14). 在 $10 \mathrm{~mol} \%\left[\mathrm{Cu}(\mathrm{MeCN})_{4}\right] \mathrm{PF}_{6}$ 为催化剂, 2 


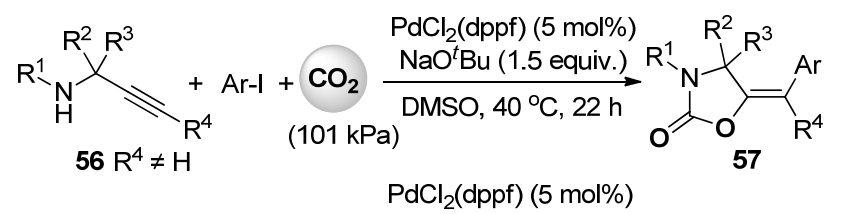

$\mathrm{PdCl}_{2}$ (dppf) (5 mol\%)

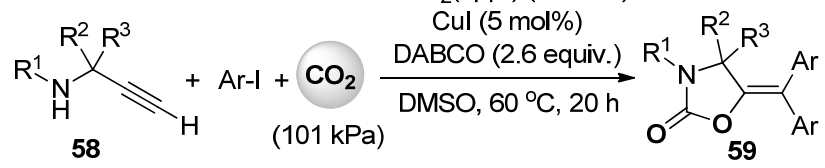

图式 13 钯催化炔丙胺, 芳基碘和二氧化碳的多组分羧化环 化反应

Scheme 13 Palladium-catalyzed multi-component carboxylative cyclization reactions of propargylamines, aryl iodides and carbon dioxide

equiv. 的 DBU 为碱, 一系列烯丙胺化合物 60 与 $101 \mathrm{kPa}$ 的二氧化碳和 Togni 试剂在室温下进行反应, 高收率, 高化学、区域及非对映异构体选择性地合成了一系列具 有重要生理活性的含三氟甲基官能团的噁唑啉酮类化 合物 61. 此反应条件温和、操作简便、可进行克级规模 制备、产物分子重要且易于衍生化. 通过一系列的对照 实验及单一非对映异构体螺环产物 61a 的晶体结构分 析, 作者推测的反应机理见 Scheme 14. 首先一价铜配 合物与 Togni 试剂之间的单电子转移产生三氟甲基自由 基的同时生成二价铜配合物，同时 $60 \mathrm{a}$ 和二氧化碳反应 得到的氨基甲酸化合物 62 与此二价铜配合物反应形成 63, 其中二氧化碳与氨基反应形成氨基甲酸酯的过程有 效地抑制了氮三氟甲基化反应形成氮杂环丙烷产物. 随 后 63 高区域及非对映体选择性地闭环得到五元杂环中 间体 64, 其中新形成的碳氧键和碳铜键呈反式构象. 64 与三氟甲基自由基结合形成高反应活性的三价铜配合 物 65 后进行还原消除得到含氟噁唑啉酮产物 61a, 同时 再生一价铜配合物催化剂(Scheme 14).

最近, 何良年课题组 ${ }^{[44]}$ 首次实现了光诱导自由基 引发的烯丙胺与二氧化碳的羧化环化反应(Scheme 15). 用全氟烷基碘化物为自由基源，1.5 equiv.的 TBD 为碱, 一系列烯丙胺化合物 66 与 $101 \mathrm{kPa}$ 的二氧化碳在可见光 照射下于室温条件下进行反应, 高收率, 高化学、区域 选择性地合成了一系列全氟烷基官能团化的噁唑啉酮 类化合物 67. 通过一系列的对照及核磁跟踪实验, 作者 推测碘全氟烷基化的氨基甲酸盐 70 是此反应的关键中 间体. 可能的反应机理见 Scheme 15. 烯丙胺化合物 66 与二氧化碳在 TBD 作用下形成氨基甲酸化合物 68. 全 氟烷基碘化物在光照条件下碳碘键均裂形成全氟烷基 自由基加成到 68 双键上得到自由基物种 69 , 随后 69 被 之前释放出的碘自由基捕捉后形成碘全氟烷基化的氨 基甲酸盐 70 (Scheme 15, Path I). 69 也可与全氟烷基碘 化物通过自由基链转移形成 $\mathbf{7 0}$, 同时生成新的全氟烷
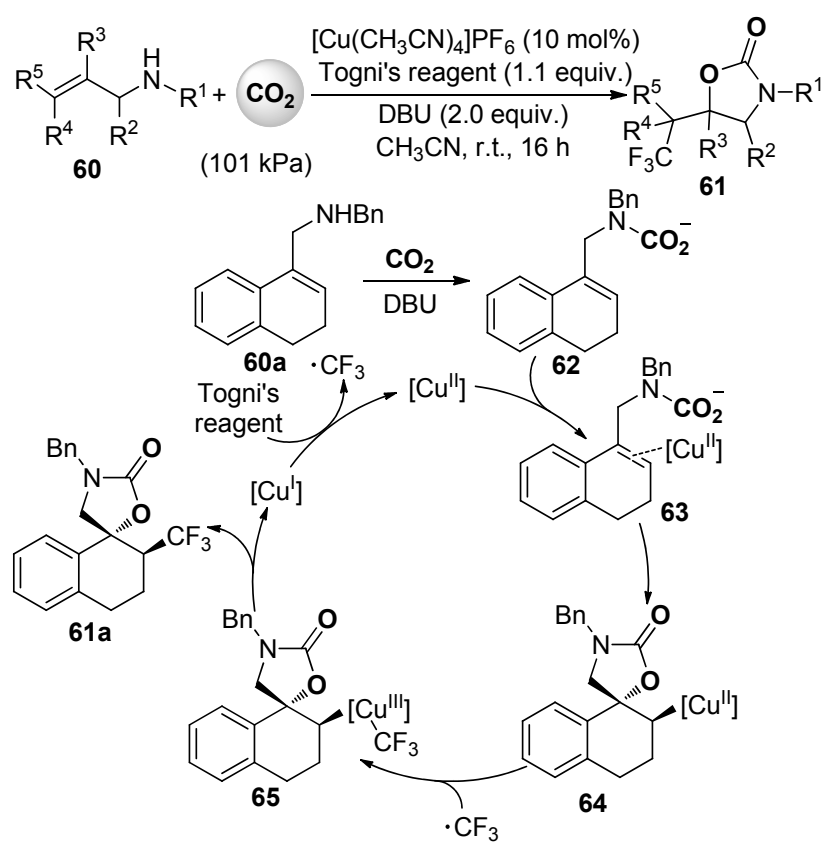

图式 14 二氧化碳参与的烯丙胺选择性氧三氟甲基化反应 Scheme 14 Selective oxytrifluoromethylation of allylamines with carbon dioxide
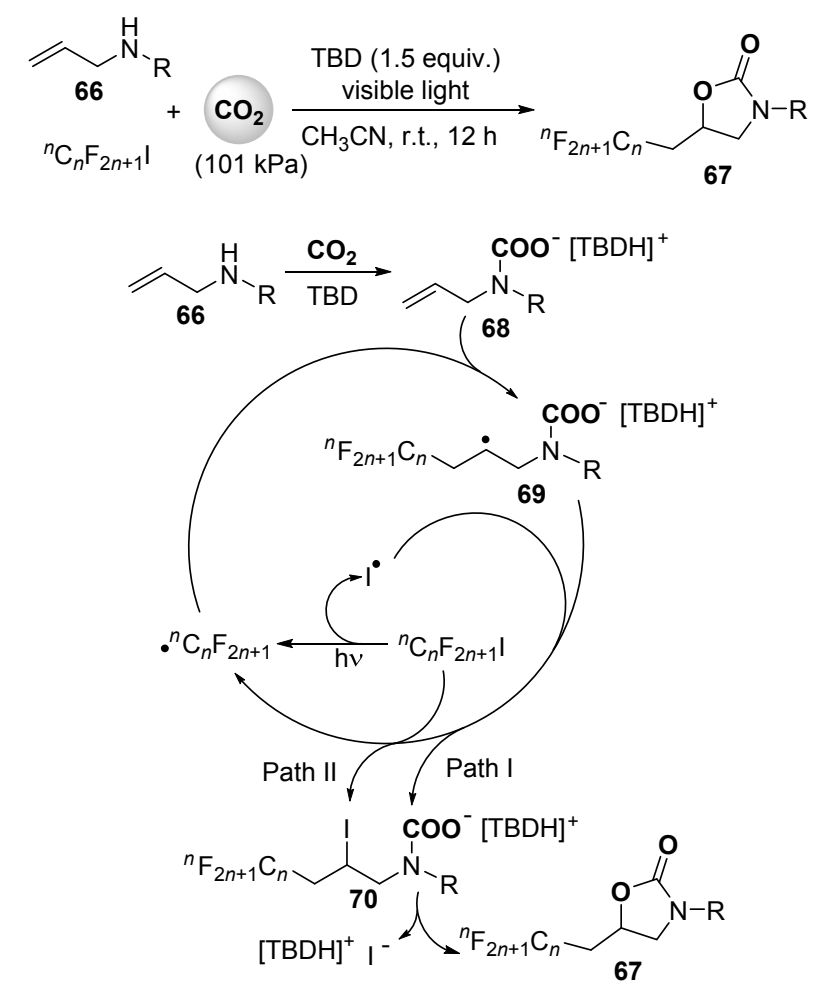

图式 15 光诱导自由基引发的烯丙胺与二氧化碳的羧化环化 反应

Scheme 15 Photoinduced radical-initiated carboxylative cyclization of allyl amines with carbon dioxide

基自由基进入下一反应循环(Scheme 15, Path II). 随后 70 发生分子内亲核取代反应得到全氟烷基取代的噁唑 
啉酮产物 67. 此光诱导自由基引发的反应体系也适用 于烯丙醇与二氧化碳的羧化环化反应合成全氟烷基取 代的环状碳酸酯产物.

2015 年, 我们课题组 ${ }^{[45]}$ 报道了无过渡金属参与的, 三(二甲氨基)膦促进的伯胺，二氧化碳与 $\alpha$-酮酸酯的多 组分羧化反应体系, 所得到产物可方便地进一步闭环得 到噁唑啉二酮类化合物 71 (Scheme 16), 此两步反应可 以通过一锅化串联反应实现. 反应过程中三(二甲氨基) 膦首先与 $\alpha$-酮酸酯反应得到高亲核反应活性的 KukhtinRamirez 加合物 72, 二氧化碳与伯胺反应得到氨基甲酸 盐 $73^{[46]}, 72$ 优先与 73 进行质子转移生成中间体 $\mathbf{7 4}$, 随 后氨基甲酸根亲核进攻释放出膦氧化合物的同时得到 氨基甲酸酯化合物 75, 其在碱催化下闭环最终得到噁 唑啉二酮产物(Scheme 16). 由于 Kukhtin-Ramirez 加合 物 72 的高亲核反应活性 ${ }^{[47]}$, 此羧化反应只需在 $101 \mathrm{kPa}$ 的二氧化碳气氛下就可顺利进行.

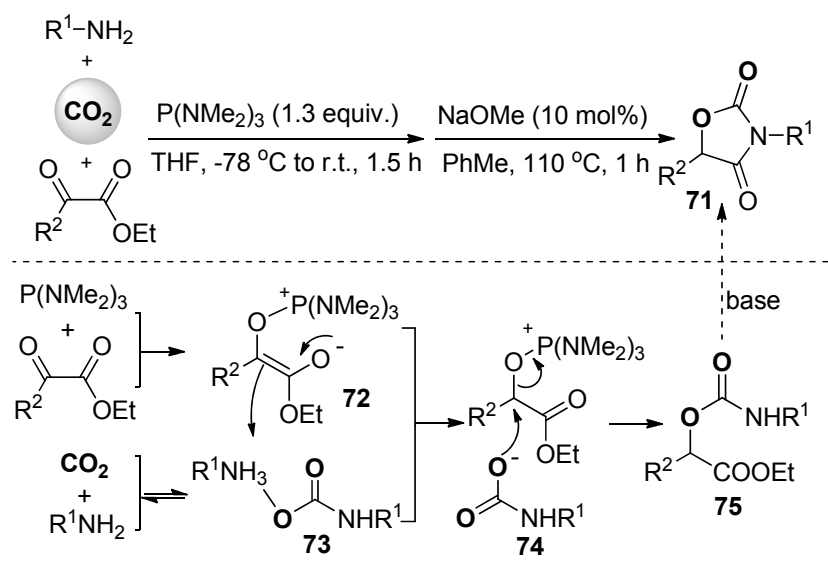

图式 16 伯胺、二氧化碳与 $\alpha$-酮酸酯的多组分羧化环化反应 Scheme 16 Multi-component carboxylative cyclization reactions of primary amines, carbon dioxide and $\alpha$-ketoesters

\section{6 合成环状碳酸酯}

二氧化碳与与环氧烷烃或炔丙醇反应合成环状碳 酸酯也是目前二氧化碳转化研究中的一类重要反 应 $^{[14 \sim 18]}$. 最近研究者发展了一些二氧化碳参与的环化 新反应合成环状碳酸酯.

2012 年, Murakami 课题组 ${ }^{[48]}$ 报道了光驱动 $\alpha$-氨基 酮 76 与二氧化碳的着化环化反应高收率合成包含酰胺 取代基的环状碳酸酯 77 (Scheme 17). 作者首先将 $\alpha$-氨 基酮底物 76 在 $101 \mathrm{kPa}$ 的二氧化碳气氛中置于太阳光下 照射 $8 \mathrm{~h}$ 后形成高能的氮杂环丁烷化合物 78, 此过程中 太阳能转化成了化学能. 接着向反应体系中加入碳酸铯 脱质子形成的 79 与二氧化碳反应得到包含碳酸根的中 间体 80, 随后碳酸根中的氧原子亲核进攻氮杂环丁烷 环, 以 5-exo-tet 型的闭环方式形成包含五元环状碳酸酯
结构的酰胺基铯盐 81 , 其质子化后得到产物 77 (Scheme 17).

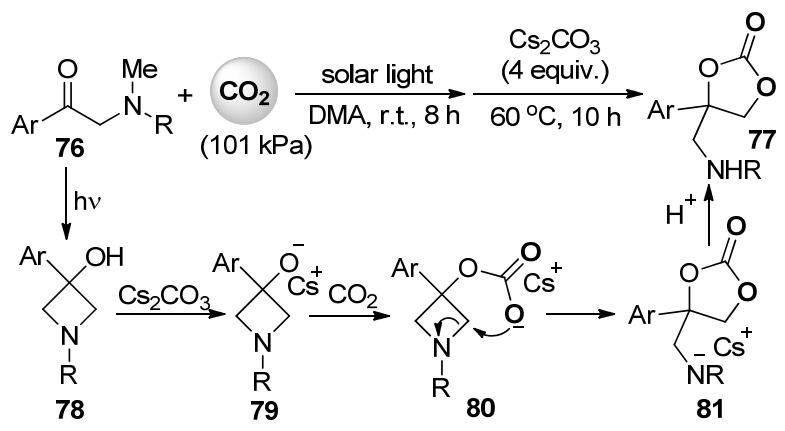

图式 17 光驱动 $\alpha$-氨基酮与二氧化碳的羧化环化反应

Scheme 17 Solar-driven carboxylative cyclization reactions of $\alpha$-amino ketones with carbon dioxide

通常情况下，在路易斯酸催化剂和亲核试剂同时存 在下，环氧丙醇/胺 82 与二氧化碳的环化反应主要通过 $\mathrm{S}_{\mathrm{N}} 2$ 过程形成环状碳酸酯 83. 最近, Kleij 课题组 ${ }^{[49]}$ 发现, 在如 Scheme 18 中所示的铝配合物催化下，反应体系中 无需外加亲核试剂时, 环氧丙醇/胺 82 与二氧化碳的环 化反应主要通过形成中间体 84 , 然后通过碳酸根中的 氧原子分子内亲核进攻 ( $\mathrm{S}_{\mathrm{N}} \mathrm{i}$ 过程)被铝配合物活化的环 氧部分, 以 5-exo-tet 型的环化方式形成五元环状碳酸酯 或噁唑啉酮 85 (Scheme 18). 当在环氧丙胺反应体系中 加入亲核性较差的碱如二异丙基乙基胺时，可促进此 $\mathrm{S}_{\mathrm{N}} \mathrm{i}$ 反应过程，从而高选择性地得到啞唑啉酮产物. 在 此基础上，作者实现了使用同一种环氧丙醇及环氧丙胺 底物通过微调反应条件(如亲核试剂的使用、碱的加入 等)控制其反应的化学选择性来合成完全不同结构的两 种环化产品.

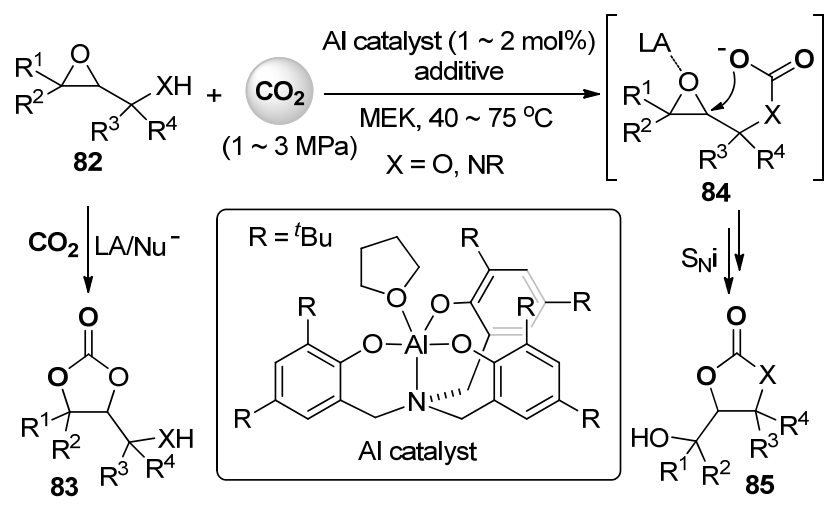

图式 18 铝配合物催化环氧丙醇/胺与二氧化碳的环化反应 Scheme 18 Aluminium-catalyzed cyclization reactions of epoxy alcohols and amines with carbon dioxide

高烯丙醇及高炔丙醇与二氧化碳的亲电环化反应 早在 2010 年已有报道. 2015 年, Johnston 课题组 ${ }^{[50]}$ 报道 了在双三氟甲基磺酰亚胺与有机催化剂 86 1: 1 组成 
的双布朗斯特酸/碱催化剂存在下, 高烯丙醇 87 与 101 $\mathrm{kPa}$ 的二氧化碳和 $N$-碘代丁二酰亚胺的不对称亲电环化 反应, 得到一系列手性的碘代六元环状碳酸酯 88 (Scheme 19). $N$-碘代丁二酰亚胺首先与高烯丙醇中的双 键形成碘离子后, 醇羟基与二氧化碳形成的碳酸根在手 性有机催化剂的作用下选择性闭环形成产物. 作者发现 双三氟甲基磺酰亚胺与有机催化剂 86 形成的氢键网络 对反应的转化率的产品的 $e e$ 值都有关键的促进作用. R 基团为间位或对位取代的芳基时，反应的对映选择性较 高, $e e$ 值超过 $90 \%$. R 基团为邻位取代的芳基时反应不能 进行. $\mathrm{R}$ 基团为烷基时, 反应的收率和的对映体选择性 略有降低. 由于产物 $\mathbf{8 8}$ 中具有高反应活性的碳碘键, 很 容易衍生化成多种在精细有机合成中有着重要用途的 手性合成子.
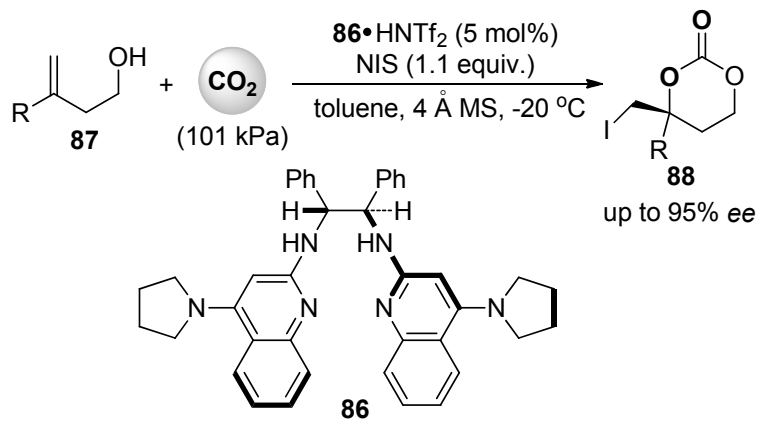

up to $95 \%$ ee

图式 19 高烯丙醇与二氧化碳的不对称亲电环化反应 Scheme 19 Enantioselective electrophilic cyclization reactions of homoallylic alcohols and carbon dioxide

最近, 成江课题组 ${ }^{[51]}$ 报道了钯催化炔丙醇, 碘代物 和 $101 \mathrm{kPa}$ 二氧化碳的多组分羧化环化反应 (Scheme 20), 以高产率合成了一系列环状碳酸酯化合物. 此反 应中零价钯与碘代物氧化加成后得到的二价钯配合物 作为路易斯酸活化炔丙醇 89 中的碳碳参键, 通过反式 氧钯化实现羧化环化后, 再经还原消除过程在双键上引 入芳基、烯基或甲基, 得到最终环状碳酸酯产物 90. 当 使用端炔丙醇底物 91 时, 只需使用过量的碘苯和添加 $10 \mathrm{~mol} \%$ 的碘化亚铜, 便可在钯催化下先进行 Sonogashira 偶联, 然后再进行多组分羧化环化反应得 到双键端位上引入两个苯基的啞唑啉酮产物 92 (Scheme 20).

最近, 侯召民课题组在他们一系列氮杂环卡宾配合 物催化的二氧化碳转化研究工作基础上 ${ }^{[52,53]}$, 发展了氮 杂环卡宾铜配合物催化的醛与联硼酸频那醇酯, 二氧化

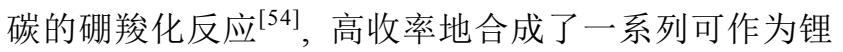
离子电池电极材料的硼杂环状碳酸酯锂化合物 93 (Scheme 21). 作者推测的反应机理中, 首先氮杂环卡宾 氯化亚铜与叔丁醇锂进行离子交换形成叔丁氧基铜配 合物 94, 经与联嗍酸频那醇酯反应后形成砋烷基铜配

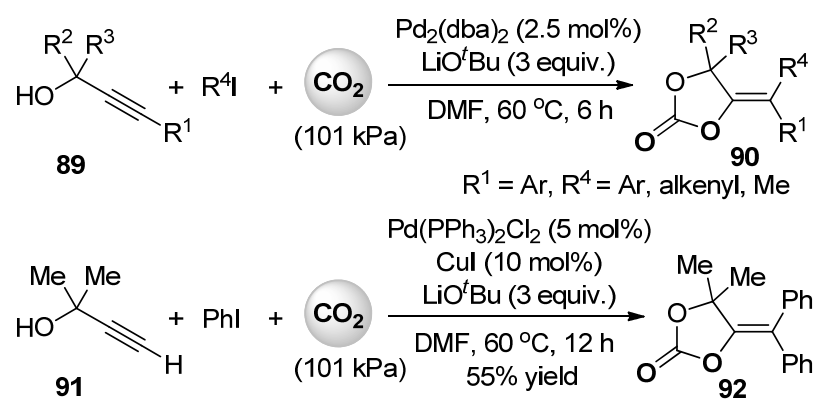

图式 20 钯催化炔丙醇、碘代物和二氧化碳的多组分羧化环 化反应

Scheme 20 Palladium-catalyzed multi-component carboxylative cyclization reactions of propargyl alcohols, organic iodides and carbon dioxide

合物 95, 随后醛插入 95 的铜硼键形成烷氧基铜中间体 96, 二氧化碳插入 96 中的铜氧键后紧接着氮杂环卡宾 铜迁移形成硣杂环状碳酸酯中间体 97 , 叔丁醇锂与 97 进行离子交换释放出产物的同时再生叔丁氧基铜配合 物 94 (Scheme 21).

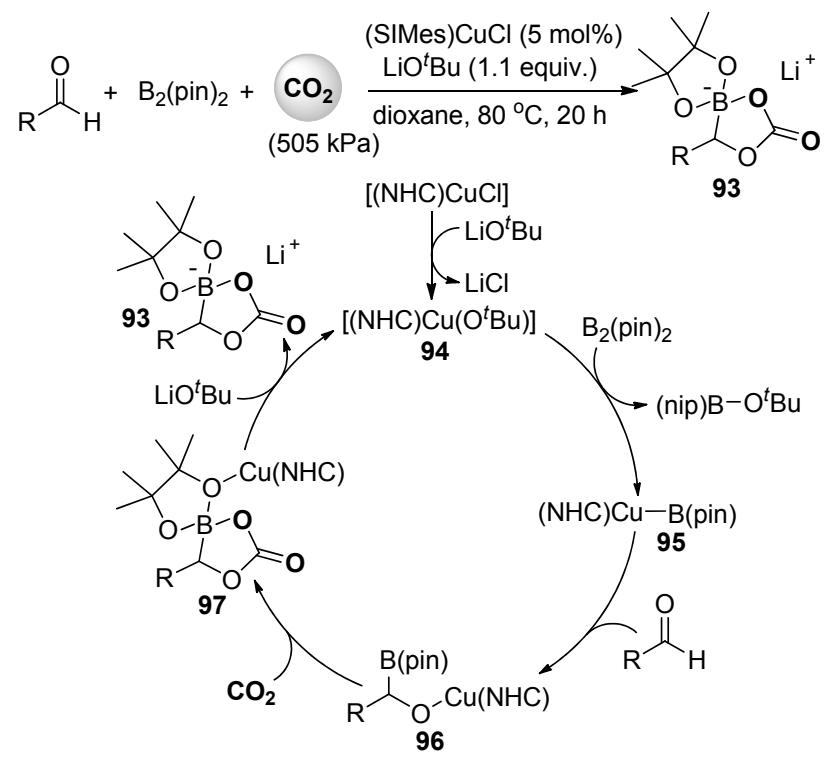

图式 21 铜催化醛与联嗍酸频那醇酯, 二氧化碳的嗍羧化反 应

Scheme 21 Copper-catalyzed bora-carboxylation reactions of aldehydes with $\mathrm{B}_{2}(\text { pin })_{2}$ and carbon dioxide

\section{7 合成苯并咪唑及苯并噻唑}

二氧化碳加氢还原是目前二氧化碳转化研究中的 热点. 而在还原剂如硅烷或硼烷等存在下, 二氧化碳可 与伯胺或仲胺进行还原性羧化环化反应得到在精细有 机合成中有着重要用途的甲胺基或甲酰胺基产物，此时 碳已从二氧化碳的 +4 价转化成低价态.

2015 年, 刘志敏课题组 ${ }^{[55]}$ 在他们之前二氧化碳转 化及离子液体研究工作基础上, 首次发展了室温条件下 
离子液体催化邻氨基苯硫酚 98 或邻苯二胺 99 与三乙氧 基硅烷, 及二氧化碳的还原性羧化环化反应, 高收率地 得到苯并噻唑 (100) 及苯并咪唑(101)类化合物 (Scheme 22). 在所使用的离子液体中，1-丁基-2,3-二甲基咪唑乙 酸盐([Bmmim][OAc])表现出最好的催化活性, 可重复 利用 5 次而不失活. 通过详细的核磁研究, 作者提出了 可能的反应机理, 见 Scheme 22. 二氧化碳首先与 $[\mathrm{Bmmim}][\mathrm{OAc}]$ 反应形成类似于氮杂环卡宾二氧化碳加 合物的中间体 102, 然后 102 中处于活化状态的二氧化 碳插入被 $[\mathrm{Bmmim}][\mathrm{OAc}]$ 活化的硅烷中的硅氢键, 形成 醛氧基硅烷中间体 103. 邻氨基苯硫酚或邻苯二胺底物 通过与离子液体中的乙酸负离子形成氢键而被活化后 再与中间体 103 反应得到甲酰胺基化合物 104, 最后分 子内脱水环化得到苯并噻唑或苯并咪唑产物. 从机理可 以看出, 离子液体对此反应中的邻氨基苯硫酚或邻苯二 胺、二氧化碳和硅烷三个反应组分都有活化作用. 最近, 李福伟 ${ }^{[5]}$ 和韩布兴 ${ }^{[57]}$ 课题组分别发现二甲基亚砜或 $\gamma$ 戊内酯同时作为溶剂和催化剂也可促进此还原性羧化 环化反应.

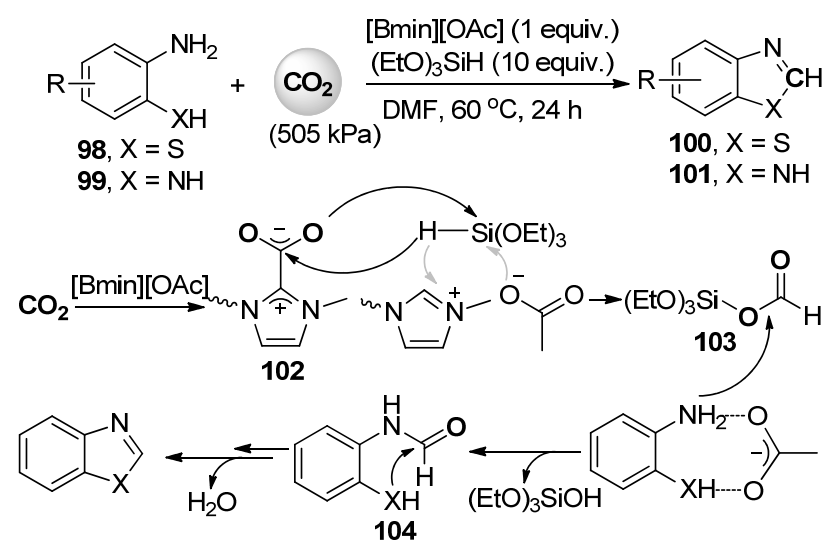

图式 22 离子液体催化邻氨基苯硫酚或邻苯二胺与硅烷、二 氧化碳的还原性着化环化反应

Scheme 22 Ionic liquid-catalyzed reductive cyclization of 2-aminothiophenols or $o$-phenylenediamines with hydrosilane and carbon dioxide

最近, 孙伟课题组 ${ }^{[58]}$ 报道了全氟苯基嗍催化邻苯 二胺与苯基硅烷、二氧化碳的还原性羧化环化反应合成 苯并咪唑类化合物 101 (Scheme 23). 机理研究发现此反 应体系中主要通过形成受阻路易酸碱对(FLP)来完成催 化循环过程. 全氟苯基硼、邻苯二胺和二氧化碳首先反 应形成 FLP 和二氧化碳的加合物 105, 接着全氟苯基硼 活化的苯基硅烷与 105 反应得到中间体 106, 随后全氟 苯基嗍离去的同时生成的甲酰胺产物经分子内脱水环 化得到苯并咪唑产物.

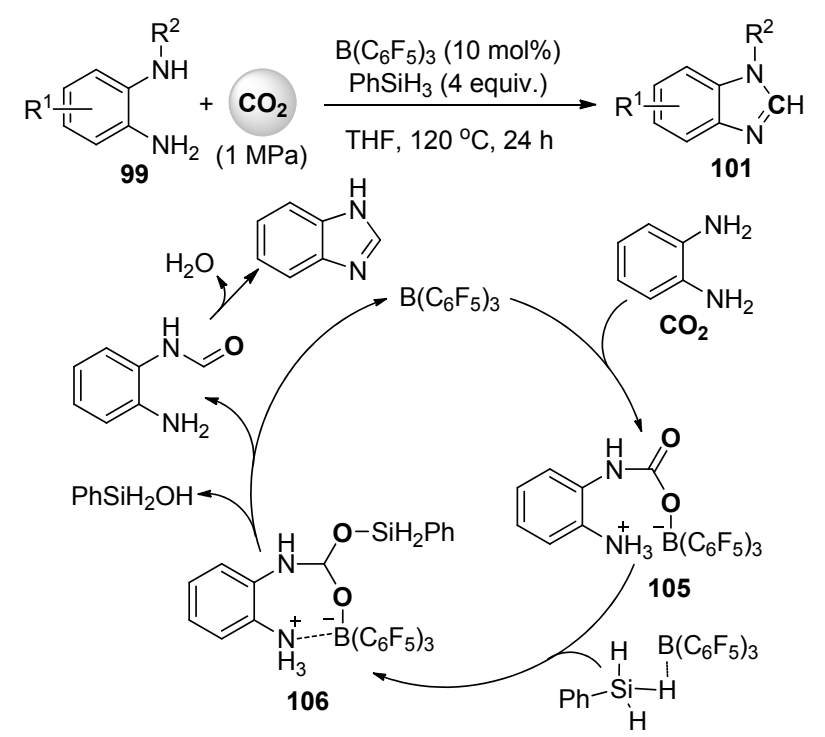

图式 23 全氟苯基嗍催化邻苯二胺与硅烷、二氧化碳的还原 性羧化环化反应

Scheme $23 \quad \mathrm{~B}\left(\mathrm{C}_{6} \mathrm{~F}_{5}\right)_{3}$-catalyzed reductive cyclization of $o$-phenylenediamines with hydrosilane and carbon dioxide

\section{8 合成环状羧酸化合物}

在许多二氧化碳作为反应底物但不参与成环过程 环化反应中，二氧化碳的插入过程可能会促进后续的成 环反应，或者先发生的环化过程产生的高活性的中间体 与二氧化碳进行后续反应最终得到环状羧酸产物.

亲电试剂如有机卤代物与二氧化碳的直接还原羧 化是目前二氧化碳催化转化中的一类重要新反应 ${ }^{[59]}$. 最近, Martin 课题组 ${ }^{\left[{ }^{[00}\right.}$ 报道了镍催化含有 $\beta$ 氢的非活化 烷基溴代物的还原性环化/二氧化碳羧化串联反应 (Scheme 24). 使用锰粉作为还原剂, 溴化镍乙二醇二甲 醚配合物与邻菲罗啉类配体组成的催化体系能有效抑 制 $\beta$ 氢消除及二聚等副反应，在室温及常压条件下便可 高效地将一系列含有 $\beta$ 氢的非活化烷基溴代物转化成相 应环状 $\alpha, \beta$-不饱和羧酸(Scheme 24). 产品的顺反构型可 以很容易地通过底物及配体的选择进行控制. 当使用伯 卤代物及配体 L1 时，反应主要得到顺式的产品 108; 当 使用仲卤代物及配体 $\mathbf{L} 2$ 时，反应主要得到反式的产品 109 (Scheme 24). 此反应条件温和, 底物适用性宽，原 料易得，操作简便，为合成两种构型的环状 $\alpha, \beta$-不饱和 羧酸提供了行之有效的方法. 虽然确切的反应机理目前 还不够清楚，但初步的实验表明羧化产物是通过一价镍 物种与二氧化碳反应得到的.

2016 年, 麻生明课题组 ${ }^{[61]}$ 报道了镍催化二炔烃 $\mathbf{1 1 0}$ 与二乙基锌和 $101 \mathrm{kPa}$ 二氧化碳的氢羧化反应, 在温和 条件下高立体及区域选择性地合成了一系列环状共轭 2,4-二烯羧酸 111 (Scheme 25). 根据详细的对照实验和 


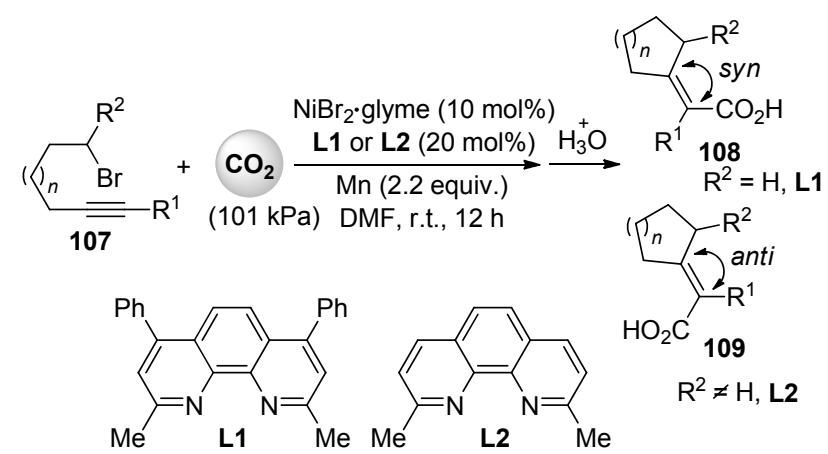

图式 24 镍催化非活化烷基溴代物的还原性环化/二氧化碳羧 化串联反应

Scheme 24 Ni-catalyzed cascade reductive cyclization/carboxylation of unactivated alkyl bromides with carbon dioxide

产物的立体及区域选择性特征，作者提出的分步反应机 理见 Scheme 25. 首先零价镍优先与反应活性更高的烷 基取代的碳碳三键配位形成中间体 112. 由于芳基取代 的碳碳三键的配位, 112 与二乙基锌的转金属化反应可 高区域选择性地进行, 得到中间体 113. $\beta$ 氢消除形成 114, 插入芳基取代的碳碳三键得到 115 , 还原消除后形 成的有机锌中间体 116 与二氧化碳进行羧化反应, 经后 处理得到环状共轭 2,4-二烯羧酸产品.
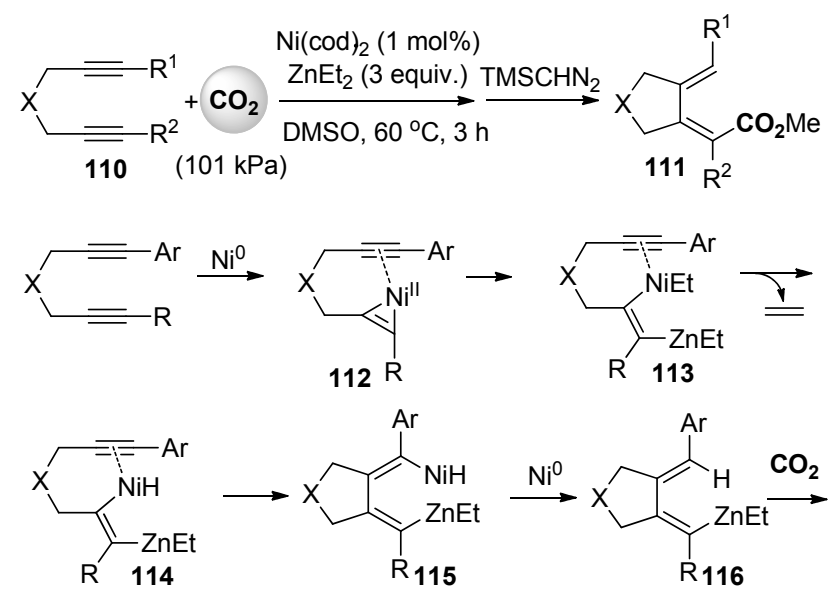

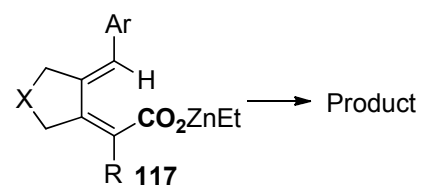

图式 25 镍催化二炔烃与二乙基锌、二氧化碳的氢羧化反应 Scheme 25 Nickel-catalyzed three-component hydrocarboxylation of diynes with diethylzinc and carbon dioxide

最近, 麻生明课题组 ${ }^{[62]}$ 也报道了邻炔基苯磺酰胺 与 $101 \mathrm{kPa}$ 的二氧化碳在 3 equiv. 的二乙基锌存在下的环 化反式氮羧化反应 (Scheme 26), 高收率地合成了包含 一系列取代基的 3-吲哚羧酸化合物. 作者提出的可能反 应机理包括底物首先与二乙基锌作用发生环化反应形
成有机锌中间体 121, 其中二乙基锌同时作为碱和活化 碳碳参键的路易斯酸. 随后二氧化碳羧化反应形成着酸 锌物种 122, 经后处理得到 3-吲哚羧酸产品. 此反应条 件温和，底物适用性宽，操作简便. 作者以此羧化反应 为基础成功合成了已商品化的药物分子 Lotronex.

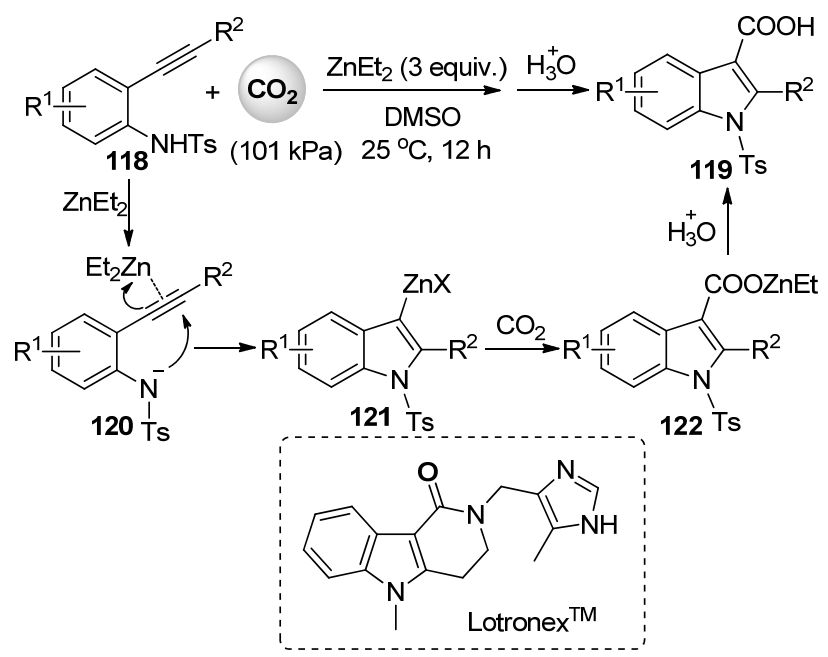

图式 26 邻炔基苯磺酰胺与二氧化碳的环化反式氮翔化反应 Scheme 26 Cyclic anti-azacarboxylation of 2-alkynylanilines with carbon dioxide

最近，我们课题组 ${ }^{[63]}$ 在之前炔基酮与二氧化碳的 羧化环化反应的基础上，发展了铜催化的邻炔基苯乙酮 123 与二氧化碳的双羧化反应(Scheme 27), 含有各种官 能团的邻炔基苯乙酮与二氧化碳进行羧化/分子内环化/ 再羧化的串联反应得到一系列异苯并呋喃类二羧酸<smiles>[R]C#Cc1ccccc1C(C)=O</smiles>

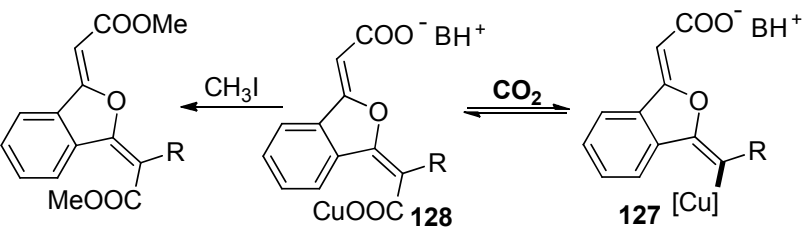

图式 27 邻炔基苯乙酮与二氧化碳的双羧化反应

Scheme 27 Double carboxylation of 2-alkynyl acetophenone with carbon dioxide 
酯产物 124. 炔基上的取代基的空间位阻对产物选择性 有着重要影响. 相比于芳基取代的炔底物, 烷基取代的 炔底物显示出更好的双羧化反应选择性. 可能的反应机 理见 Scheme 27. 邻炔基苯乙酮首先与一分子的二氧化 碳在碱作用下形成 $\beta$ 酮酸中间体 $\mathbf{1 2 5}$, 接着 125 中的烯 醇式氧原子进攻被一价铜活化的碳碳参键得到包含碳 铜键的中间体 127 , 另外一分子二氧化碳插入后形成的 羧基铜物种 128 与碘甲烷反应得到双羧化的羧酸酯产 物.

\section{9 总结与展望}

将二氧化碳作为廉价易得的可再生碳源, 通过环化 反应将其转化成高附加值的环状产物的研究有了重要 进展. 二氧化碳可以和一系列高能试剂反应得到内酰 胺、内酯、邻苯二甲酰亚胺、环状酸酐、噁唑啉酮、环 状碳酸酯、苯并噻唑及苯并咪唑等重要的杂环化合物. 其中有些高效的环化反应由于操作简便，容易放大，具 有在精细有机合成生产中替代传统方法而实际应用的 巨大潜力. 但从总体上来说, 由于二氧化碳的反应惰性, 其参与的环化反应类型还不够丰富. 大部分环化反应还 需在高温高压下或过渡金属催化剂存在下进行. 光驱动 的二氧化碳参与的环化反应虽有报道但底物适用性不 够广泛. 因此, 在发展传统的单一依靠化学能转化的二 氧化碳环化反应的同时, 通过引入光、电等其他形式的 能量, 发展新型的、反应类型更加丰富的、产品结构更 加多样且实用的高效二氧化碳环化反应是可以期望的 重要突破点.

\section{Referenes}

[1] Sakakura, T.; Choi, J.-C.; Yasuda, H. Chem. Rev. 2007, 107, 2365.

[2] He, M.; Sun, Y.; Han, B. Angew. Chem., Int. Ed. 2013, 52, 9620.

[3] Aresta, M.; Dibenedetto, A.; Angelini, A. Chem. Rev. 2014, 114, 1709.

[4] Liu, Q.; Wu, L.; Jackstell, R.; Beller, M. Nat. Commun. 2015, 6, 5933.

[5] He, L.-N. Carbon Dioxide Chemistry, Science Publisher, Beijing, 2013 (in Chinese) (何良年, 二氧化碳化学, 科学出版社, 北京, 2013.)

[6] Huang, K.; Sun, C. L.; Shi, Z.-J. Chem. Soc. Rev. 2011, 40, 2435

[7] Tsuji, Y.; Fujihara, T. Chem. Commun. 2012, 48, 9956.

[8] Yang, Z.-Z.; He, L.-N.; Gao, J.; Liu, A.-H.; Yu, B. Energy Environ. Sci. 2012, 5, 6602.

[9] Cai, X.; Xie, B. Synthesis 2013, 45, 3305.

[10] Wang, S.; Du, G.; Xi, C. Org. Biomol. Chem. 2016, 14, 3666.

[11] Yu, B.; Liu, Z. M. Chin. Sci. Bull. 2015, 60, 1452 (in Chinese). (于博, 刘志敏, 科学通报, 2015, 60, 1452.)

[12] Yu, B.; He, L.-N. ChemSusChem 2015, 8, 52

[13] Rintjema, J.; Kleij, A. W. Synthesis 2016, 48, 3863.

[14] Lu, X.-B.; Darensbourg, D. J. Chem. Soc. Rev. 2012, 41, 1462.

[15] Kielland, N.; Whiteoak, C. J.; Kleij, A. W. Adv. Synth. Catal. 2013, $355,2115$.

[16] Xu, B.-H.; Wang, J.-Q.; Sun, J.; Huang, Y.; Zhang, J.-P.; Zhang, X.-P.; Zhang, S.-J. Green Chem. 2015, 17, 108

[17] Martin, C.; Fiorani, G.; Kleij, A. W. ACS Catal. 2015, 5, 1353.
[18] Lang, X.-D.; He, L.-N. Chem. Rec. 2016, 16, 1337.

[19] Manjolinho, F.; Arndt, M.; Gooßen, K.; Gooßen, L. J. ACS Catal. 2012, 2, 2014.

[20] Zhu, Q.; Wang, L.; Xia, C.; Liu, C. Chin. J. Org. Chem. 2016, 36, 2813 (in Chinese) (朱庆, 王露, 夏春谷, 刘超, 有机化学, 2016, 36, 2813.)

[21] Zhang, Z.; Liao, L.-L.; Yan, S.-S.; Wang, L.; He, Y.-Q.; Ye, J.-H.; Li, J.; Zhi, Y.-G.; Yu, D.-G. Angew. Chem., Int. Ed. 2016, 55, 7068.

[22] Zhang, Z.; Ju, T.; Ye, J.-H.; Yu, D.-G. Synlett 2017, 28, 741.

[23] Wang, S.; Shao, P.; Du, G.; Xi, C. J. Org. Chem. 2016, 81, 6672.

[24] Villiers, C.; Dognon, J.-P.; Pollet, R.; Thuery, P.; Ephritikhine, M. Angew. Chem., Int. Ed. 2010, 49, 3465.

[25] Sun, S.; Hu, W.-M.; Gu, N.; Cheng, J. Chem. Eur. J. 2016, 22, 18729.

[26] Sasano, K.; Takaya, J.; Iwasawa, N. J. Am. Chem. Soc. 2013, 135 , 10954.

[27] Zhang, Z.; Ju, T.; Miao, M.; Han, J.-L.; Zhang, Y.-H.; Zhu, X.-Y.; Ye, J.-H.; Yu, D.-G.; Zhi, Y.-G. Org. Lett. 2017, 19, 396.

[28] Xin, Z.; Lescot, C.; Friis, S. D.; Daasbjerg, K.; Skrydstrup, T. Angew. Chem., Int. Ed. 2015, 54, 6862.

[29] Bhunia, A.; Yetra, S. R.; Biju, A. T. Chem. Soc. Rev. 2012, 41, 3140.

[30] Yoshida, H.; Fukushima, H.; Ohshita, J.; Kunai, A. J. Am. Chem. Soc. 2006, 128, 11040.

[31] Yoo, W.-J.; Nguyen, T. V. Q.; Kobayashi, S. Angew. Chem., Int. Ed. 2014, 53, 10213 .

[32] Zhang, W.-Z.; Li, W.-J.; Zhang, X.; Zhou, H.; Lu, X.-B. Org. Lett. 2010, 12, 4748.

[33] Flowers, B. J.; Gautreau-Service, R.; Jessop, P. G. Adv. Synth. Catal. 2008, 350, 2947.

[34] Sekine, K.; Ishida, T.; Yamada, T. Angew. Chem., Int. Ed. 2012, 51, 6989.

[35] Sekine, K.; Takayanagi, A.; Kikuchi, S.; Yamada, T. Chem. Commun. 2013, 49, 11320

[36] Zhang, W.-Z.; Shi, L.-L.; Liu, C.; Yang, X.-T.; Wang, Y.-B.; Luo, Y.; Lu, X.-B. Org. Chem. Front. 2014, 1, 275.

[37] Zhang, W.-Z.; Liu, S.; Lu, X.-B. Beilstein J. Org. Chem. 2015, 11, 906 .

[38] Zhang, W.-Z.; Yang, M.-W.; Lu, X.-B. Green Chem. 2016, 18, 4181.

[39] Masuda, Y.; Ishida, N.; Murakami, M. J. Am. Chem. Soc. 2015, 137,14063

[40] Kaicharla, T.; Thangaraj, M.; Biju, A. T. Org. Lett. 2014, 16, 1728.

[41] Fujihara, T.; Horimoto, Y.; Mizoe, T.; Sayyed, F. B.; Tani, Y.; Terao, J.; Sakaki, S.; Tsuji, Y. Org. Lett. 2014, 16, 4960.

[42] Garcia-Dominguez, P.; Fehr, L.; Rusconi, G.; Nevado, C. Chem. Sci. 2016, 7, 3914

[43] Ye, J.-H.; Song, L.; Zhou, W.-J.; Ju, T.; Yin, Z.-B.; Yan, S.-S.; Zhang, Z.; Li, J.; Yu, D.-G. Angew. Chem., Int. Ed. 2016, 55, 10022.

[44] Wang, M.-Y.; Cao, Y.; Liu, X.; Wang, N.; He, L.-N.; Lia, S.-H. Green Chem. 2017, 19, 1240

[45] Zhang, W.-Z.; Xia, T.; Yang, X.-T.; Lu, X.-B. Chem. Commun. 2015, 51, 6175 .

[46] Zhang, W.-Z.; Ren, X.; Lu, X.-B. Chin. J. Chem. 2015, 33, 610.

[47] Miller, E. J.; Zhao, W.; Herr, J. D.; Radosevich, A. T. Angew. Chem., Int. Ed. 2012, 51, 10605 .

[48] Ishida, N.; Shimamoto, Y.; Murakami, M. Angew. Chem., Int. Ed. 2012, 51,11750

[49] Rintjema, J.; Epping, R.; Fiorani, G.; Martin, E.; Escudero-Adan, E. C.; Kleij, A. W. Angew. Chem., Int. Ed. 2016, 55, 3972.

[50] Vara, B. A.; Struble, T. J.; Wang, W.; Dobish, M. C.; Johnston, J. N. J. Am. Chem. Soc. 2015, 137, 7302,

[51] Sun, S.; Wang, B.; Gu, N.; Yu, J.-T.; Cheng, J. Org. Lett. 2017, 19 , 1088.

[52] Zhang, L.; Hou, Z. Chem. Sci. 2013, 4, 3395.

[53] Zhang, S.; Li, X.-D.; He, L.-N. Acta Chim. Sinica 2016, 74, 17 (in Chinese).

(张帅, 李雪冬, 何良年, 化学学报, 2016, 74, 17.) 
[54] Carry, B.; Zhang, L.; Nishiura, M.; Hou, Z. Angew. Chem., Int. Ed. 2016, 55, 6257.

[55] Gao, X.; Yu, B.; Yang, Z.; Zhao, Y.; Zhang, H.; Hao, L.; Han, B.; Liu, Z. ACS Catal. 2015, 5, 6648.

[56] Lv, H.; Xing, Q.; Yue, C.; Lei, Z.; Li, F. Chem. Commun. 2016, 52, 6545 .

[57] Song, J.; Zhou, B.; Liu, H.; Xie, C.; Meng, Q.; Zhang, Z.; Han, B. Green Chem. 2016, 18, 3956.
[58] Zhang, Z.; Sun, Q.; Xia, C.; Sun, W. Org. Lett. 2016, 18, 6316.

[59] Borjesson, M.; Moragas, T.; Gallego, D.; Martin, R. ACS Catal. 2016, 6, 6739 .

[60] Wang, X.; Liu, Y.; Martin, R. J. Am. Chem. Soc. 2015, 137, 6476.

[61] Cao, T.; Ma, S. Org. Lett. 2016, 18, 1510.

[62] Miao, B.; Li, S.; Li, G.; Ma, S. Org. Lett. 2016, 18, 2556.

[63] Zhang, W.-Z.; Yang, M.-W.; Yang, X.-T.; Shi, L.-L.; Wang, H.-B.; Lu, X.-B. Org. Chem. Front. 2016, 3, 217. 